\title{
VIBRATION CHARACTERISTICS OF RECIPROCATING AIR COMPRESSORS USED FOR HYPERBARIC PURPOSES
}

\author{
Marcin Kluczyk
}

Institute of Technical Operation of Ships, Polish Naval Academy in Gdynia, Poland

\section{ABSTRACT}

The article presents problems related to the diagnostics of vibrations in reciprocating compressors driven by motors of less than $100 \mathrm{~kW}$. None of the currently applicable norms concerning the issues of vibration diagnostics broach this subject, and therefore diagnosticians have no reference levels for measured vibration parameters. The present paper focuses on two types of compressors intended for diving purposes and hyperbaric techniques. The paper contains a suggested course of actions at the time of taking measurements. Further suggestions for developing coherent procedures as regards the diagnostics of reciprocating compressors of less than $100 \mathrm{~kW}$ have been indicated. Key words: Reciprocating compressors, vibration diagnostics.

ARTICLE INFO

PolHypRes 2015 Vol. 52 Issue 3 pp. 17-28

ISSN: 1734-7009 elSSN: 2084-0535

DOI: 10.1515/phr-2015-0013

Pages: 12, figures: 11, tables: 1

page www of the periodical: www.phr.net.pl

Publisher

Polish Hyperbaric Medicine and Technology Society
Original article

Delivery date: $07.07 .2015 \mathrm{r}$.

Date of approval for print: 11.08.2015r. 


\section{INTRODUCTION}

The operating principle of all reciprocating machines assumes that, during their operation, unsustainable forces are formed which cause cyclostationary (periodical) vibrations in the function of the crankshaft rotation. These vibrations are unavoidable even in a well-functioning device. In principle, with the deterioration of the technical condition of a reciprocating device, its dynamic characteristics change too, most typically for the worse, which must be interpreted as an increase of vibroactivity of the device. On account of their complexity, issues related to vibration diagnostics of reciprocating machines are rather complex. This is probably the reason why all issues related to the diagnostics of machines of less than $100 \mathrm{~kW}$ have not been fully regulated.

From the point of view of technical diagnostics, the best results are achieved when continuous measurements of vibration parameters are performed and their trends are observed. Such solutions are used in the case of diagnostics for critical machines in industry. Critical machines include nearly all hyper compressors commonly used in the petroleum industry. The continuous measuring of vibration parameters, as well as the archiving of this data, means considerable costs accompany the device's installation,there are also subsequent costs related to the support of the diagnostic staff indispensable for the maintenance system. Certainly, these expenses are later offset by the savings that result from extended periods between repairs and avoiding unexpected downtime of the devices [12].

In the case of smaller devices that do not have the characteristics of critical machines, the application of on-line measurements of vibration parameters is usually unjustified. Alternatively, periodical or, in exceptional cases, occasional measurements are performed. In the case of periodical measurements, it is possible to prepare a graphical representation of the trend as regards selected parameters (less accurate than in the case of online measurements), whereas for single-time measurements the best solution appears to be a reference to standards.

However, there are no unambiguous guidelines for acceptable levels of vibration parameters in the aspect of measurements in low capacity reciprocating compressors. In such cases the diagnostician must rely on his own experience. In the following sections of this paper the author focuses on the analysis of vibration parameters in two reciprocating compressors that are available at the Department of Underwater Works Technology of the Polish Naval Academy in Gdynia.

\section{AN OVERVIEW OF MANDATORY}

\section{STANDARDS}

All standards and recommendations related to measurements of reciprocating machines are consistent with minimum requirements in relation to the equipment used for taking measurements, the manner in which sensors are installed as well as their placement in relation to one another $[2,3,7,9,10]$. Inconsistencies occur in the place where transducers are installed, hence the compressors' heads were selected as spots for taking measurements on account of their potential to be the areas of highest vibroactivity. The spots for installation are also in the proximity of suction and discharge valves, which is conducive to the reception of signals that enable valve diagnostics.

The standards that relate to the issues of vibration diagnostics are included in the ISO 10816-(1-9) series. Most of them do not have their equivalents in Polish Standards (with the exception of the 'PN-ISO10816-1 standard: Mechanical vibrations - an evaluation of the vibrations of a machine on the basis of the measurements taken on non-rotating parts). Directly related to the issues of the measurements of vibration parameters in reciprocating machines is the 'ISO 10816-6' standard: Mechanical vibration - Evaluation of machine vibration by measurements on non-rotating parts- Part 6: Reciprocating machines with power ratings above 100 $\mathrm{kW}$.

This standard is nearly identical to the German VDI 2056 standard, with the exception that there are11 instead of 13 levels of intensity included in VDI 2056. The capacity of the compressors under scrutiny is significantly lower than $100 \mathrm{~kW}$, however, it appears legitimate to mention the reference values for vibration velocity in the abovementioned norm. Allowable values of vibration parameters included in the ISO 10816-6 have been presented in Table 1. 


\begin{tabular}{|c|c|c|c|c|c|c|c|c|c|c|c|}
\hline & \multicolumn{4}{|c|}{ Maximum value } & \multicolumn{7}{|c|}{ Group the machine was qualified to } \\
\hline & & & & & 1 & 2 & 3 & 4 & 5 & 6 & 7 \\
\hline $\begin{array}{c}\text { Degree of } \\
\text { Vibration severity }\end{array}$ & 莺 & $\begin{array}{l}\stackrel{D}{0} \\
\stackrel{0}{0} \\
\frac{0}{0} \\
>\end{array}$ & 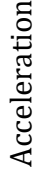 & 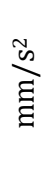 & \multicolumn{7}{|c|}{ Designated zones } \\
\hline
\end{tabular}

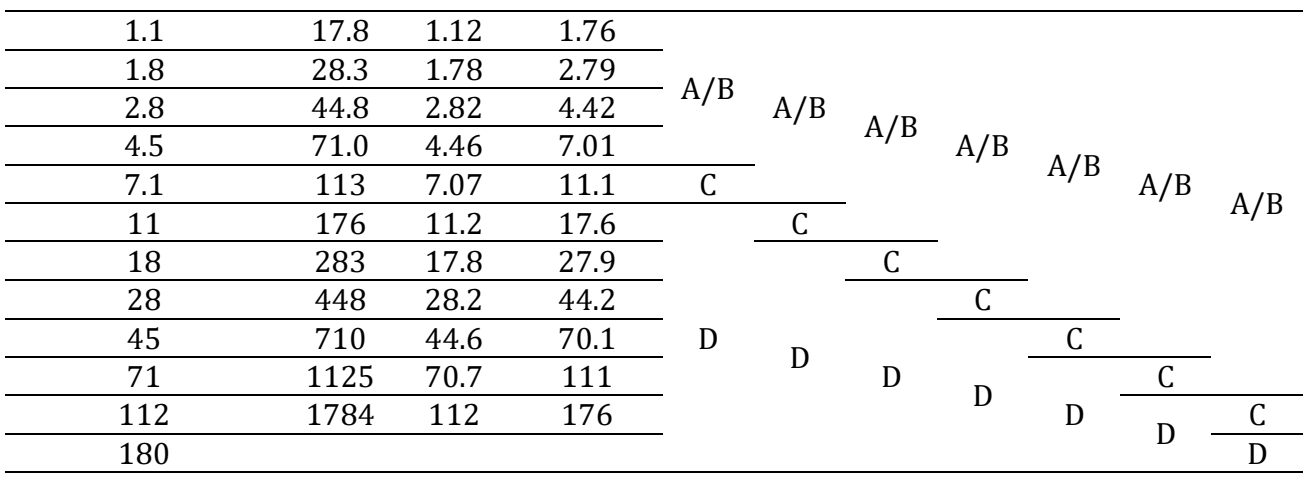

- Zone A - new machines

- Zone $\mathrm{B}$ - machines with vibrations that do not affect their long-term use.

- Zone $\mathrm{C}$ - machines where the vibration level has been exceeded, which can be used conditionally until repairs have been conducted

- Zone D - machines where vibrations are so intense that their further use leads to serious damage.

A machine is qualified to a given zone (A-D) after the determination of one of the vibration parameters in the frequency range from $10 \mathrm{~Hz}$ to $1 \mathrm{kHz}$. The content of the standard does not provide guidelines as regards the principles of qualification to each of the groups (from 1 to 7 ). It is assumed that reciprocating engines need to be qualified to groups 5-7, whereas reciprocating compressors to groups 4-5. All the other more detailed qualifications need to be implemented after consultations with the user.
Figure 1 presents the recommended distribution of sampling points on reciprocating machines with a vertical axis. The text of the ISO 10816-1 standard also includes entries concerning reciprocating machines, but in the classification of machine groups for which values of reference were provided, reciprocating machines are no longer on the list, therefore this standard will not be referred to in further sections of this paper.

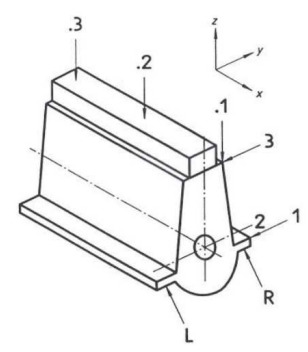

Fig. 1. An exemplary distribution of sampling points on a reciprocating machine with respect to ISO 10816-6 [9].

One disadvantage of the ISO 10816-6 standard is that it was made for the purposes of reciprocating engines. This standard does not define the classification of reciprocating compressors, nor does it differentiate between guiding values for different parts of the compressor, it only indicates the location of sampling points shown on fig 1 .

Slightly more detailed guidelines as to the interpretation of the results obtained when measuring vibrations of reciprocating compressors are provided by the EFRC (the European Forum for Reciprocating Compressors) [2]. However, it should be underlined that this organisation is only concerned with the largest industrial compressors, chiefly those applied in the petrochemical industry. 


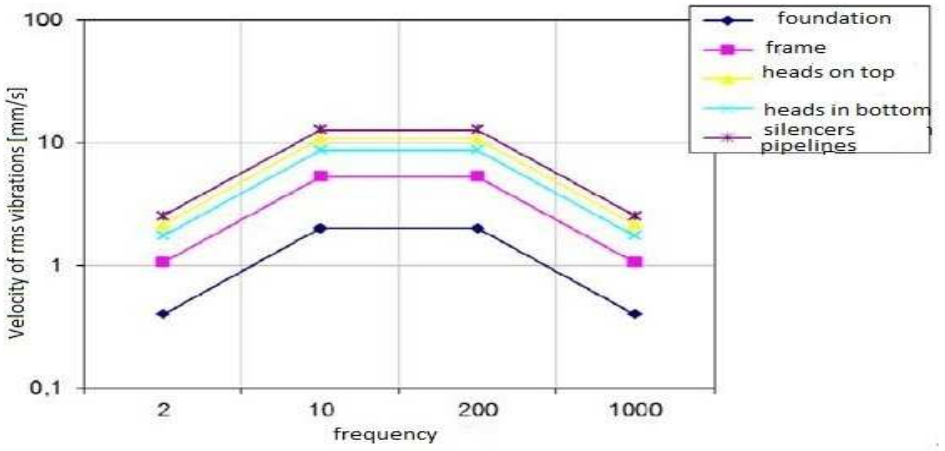

Fig. 2. Curves that define allowable rms velocities of vibrations in the elements of vertical compressors that may be qualified to $A / B$ zones.

Undoubtedly, one of the advantages of EFRC guidelines is the list of limiting values for individual compressor elements. These guidelines are an extension of the ISO 10816-6 standard, and therefore the author does not repeat zone descriptions (A-D - table 1).

The last normative document that needs to be mentioned is the Defence Standard N0-20-A500-3 [11]. This standard does not distinguish between the devices with respect to their power, therefore the examination of the compressor may be qualified to group B - units with electric motors. The standard gives limiting values for $1 / 3$ octave bandswith mid-band frequencies from 1 to $500 \mathrm{~Hz}$, which in turn enables a more accurate comparison of the spectrum in narrowband intervals than the standards previously mentioned which allow for one band in the interval from 10 to $1 \mathrm{kHz}$.

\section{OBJECTS OF RESEARCH}

Two varying compressor types have been tested in the course of the conducted measurements. First was an SC1-115 series compressor with a maximum delivery pressure of $3 \mathrm{MPa}$ and productivity of $48 \mathrm{~m}^{3} / \mathrm{h}$, manufactured at Cegielski-Sulzer. Figure 1 presents a section of the compressor. The nominal speed of the compressor rotation is $970 \mathrm{rev} / \mathrm{min}$. Constructions of this type of compressors are relatively old, but still in common use.

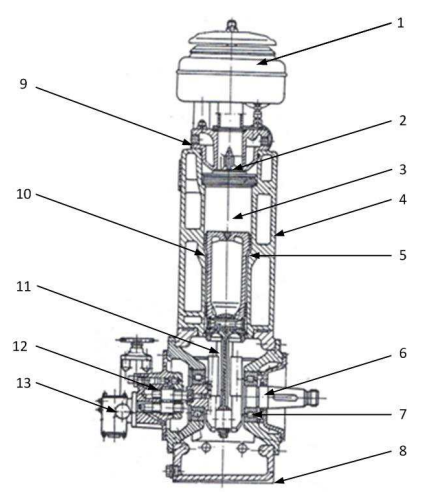

Fig. 3. A section of the SC1-115 compressor with the most essential elements marked. 1 - air filter, 2 - suction-delivery valve of the $1^{\text {st }}$ stage, $3-$ differential piston, 4 - cylinder block, 5 - delivery valve of the $2^{\text {nd }}$ stage, 6 - crankshaft, 7 - rolling bearings, 8 - crankcase, 9 - head, 10 - suction valve of the $2^{\text {nd }}$ stage, 11 - connecting rod, 12 - circulating oil pump, 13 - lubrication pump.

The demonstrated compressor is a two-stage, single-acting reciprocating compressor with a vertical set of cylinders and a differential piston. It is driven by an electric motor with a jaw clutch. It is equipped with an automatic suction-delivery plate valve on the $1^{\text {st }}$ stage and two automatic plate valves of the $2^{\text {nd }}$ stage, a suction and a delivery valve. Valves of this type are the most vulnerable elements of compressors and therefore particular attention should be paid to by the diagnostician $[1,4,5,6]$. However, other elements that work for the wellbeing of the entire unit must not be overlooked.

The other examined device was an MCH-13/ET STANDARD compressor by Aertotecnica Coltri - fig 3. This compressor has been constructed specially for hyperbaric purposes, and more specifically refilling cylinders. The SC1-115 compressor has only been adapted for securing the work of hyperbaric chambers. The $\mathrm{MCH}$ compressor is a three-stage, three-piston compressor driven by an electric motor with belt transmission. The velocity of the electric motor is 2840 [rev/min] and the compressor - 1350 [rev/min]. All stages of the compressor have one suction valve and one delivery valve each. 

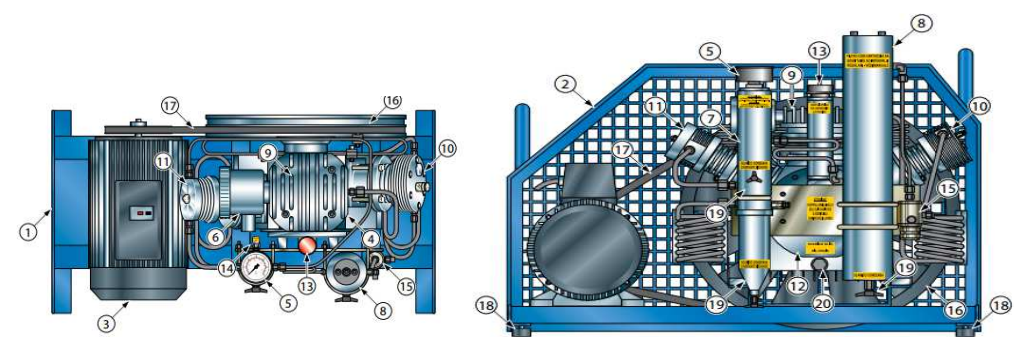

Fig. 3. Elements of the MCH-8 -11/EM STANDARD compressor. 1 - frame, 2 - cover, 3 - propulsion engine, 4 - compressor, 5 - manometer, 6 - air filter, 7 - separator , 8 - carbon filter, $9-1^{\text {st }}$ stage , $10-2^{\text {nd }}$ stage, $11-3^{\text {rd }}$ stage, 12 - monoblock, 13 - oil drain screw, $14-$ safety valve, $15-$ control valve, 16 - fan, 17 - drive belt, 18 - shock absorber, 19 - decompression valve, 20 - oil drain screw [11].

What is unusual about this compressor is its crank and piston system presented in figure 4. The transfer from a rotary motion to a reciprocating motion is realised here with the use of a $\mathrm{W}$ type crank and piston system.

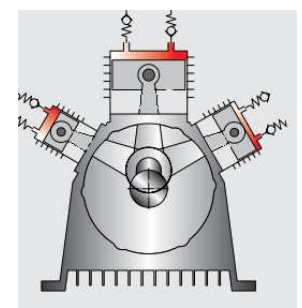

Fig. 4 Crank and piston system of the $\mathrm{MCH}$ compressor.

\section{COURSE OF MEASUREMENTS AND TEST}

\section{RESULTS}

In the course of measurements, time waveforms of vibration acceleration were recorded. For this purpose, B\&K type $4514 \mathrm{~B}$ accelerometers were used together with a type 3650-B-120 five channel measuring cassette. The vibrations were measured in the band between $1 \mathrm{~Hz}$ to $12.8 \mathrm{kHz}$ with the sampling rate of $32768 \mathrm{~Hz}$. All elements of the measuring system complied with the standards that concern the issue of vibrations.

The sensors were installed on the tested devices with a magnetic base. The sensor-magnetic base unit is characterised by the resonant frequency in the range of 5$7 \mathrm{kHz}$,for which reason the analyses within this range were not examined. Methods of analysis that are based on amplitude changes in the resonant bandwidth of the sensor and the base do exist, but to obtain these it is necessary to be in possession of the results of earlier measurements and impulse characteristics of the signal $[9,10]$, however in this case, only our own recordings were available. The bibliography analysis indicates that the most commonly occurring damage to reciprocating compressors happens at the automatic valves $[1,8,12]$. Therefore, compressor heads near installation spots for valves of all stages, were selected as measurement spots. Measurements were taken during normal operation of the devices, no damage or interference was simulated.

Test analyses were performed in the Pulse LabShop and Pulse Reflex environment. First, the recorded data was analysed in the domain of time. An example of a time waveform is shown in figure 5.

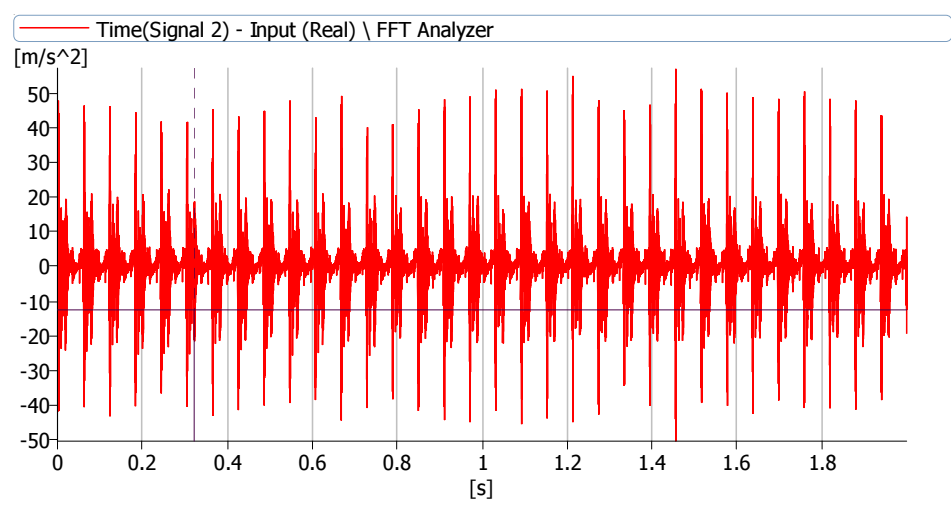

Fig. 5. A time waveform of the SC1 compressor vibration accelerations 
By narrowing the time waveform of observation, and accounting for the absolute value of vibration accelerations, we obtain the waveform shown in figure 6 . For a waveform presented in such a manner we are able to indicate lines related to respective events that result from the operation of the compressor.

$$
\text { The time between each of the events }
$$
corresponds to the time of one revolution of the compressor's crankshaft, which means that for the velocity of $970 \mathrm{rev} / \mathrm{min}$ corresponds $\mathrm{t}=0.062 \mathrm{~s}$. If we were to compare waveforms prepared in such a manner, obtained in established diagnostic periods, we would be in a position to determine the technical condition of the valves (e.g. valve spring wear).

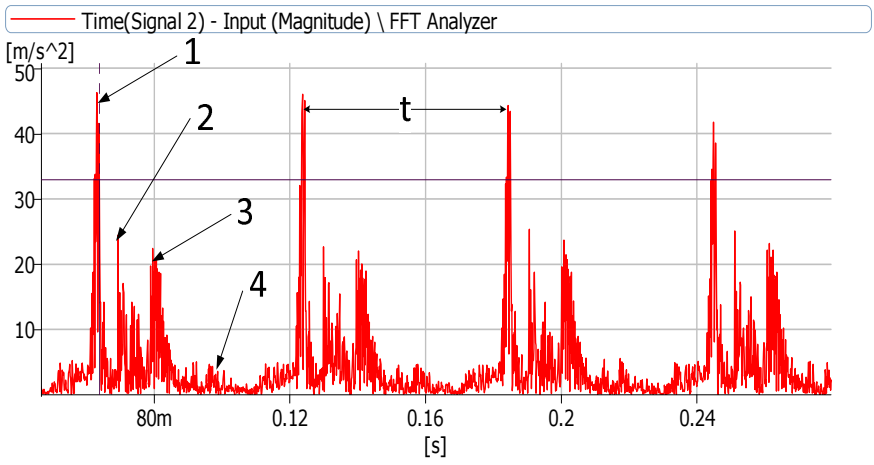

Fig. 6. Absolute values of the SC1 compressor vibration accelerations. 1 - opening of the delivery valve, 2 - closure of the delivery valve, top dead centre, 3 - opening of the suction valve, 4 - closure of the suction valve, bottom dead centre, $t$ - time taken for one full revolution of the crankshaft.

Another stage of the analyses was a change of the vibration course domain from time to frequency. For this purpose, the fast Fourier transform with the Hann window and a single integration were used. Owing to this amplitude frequency waveforms of vibration velocities were obtained-figure 7 .
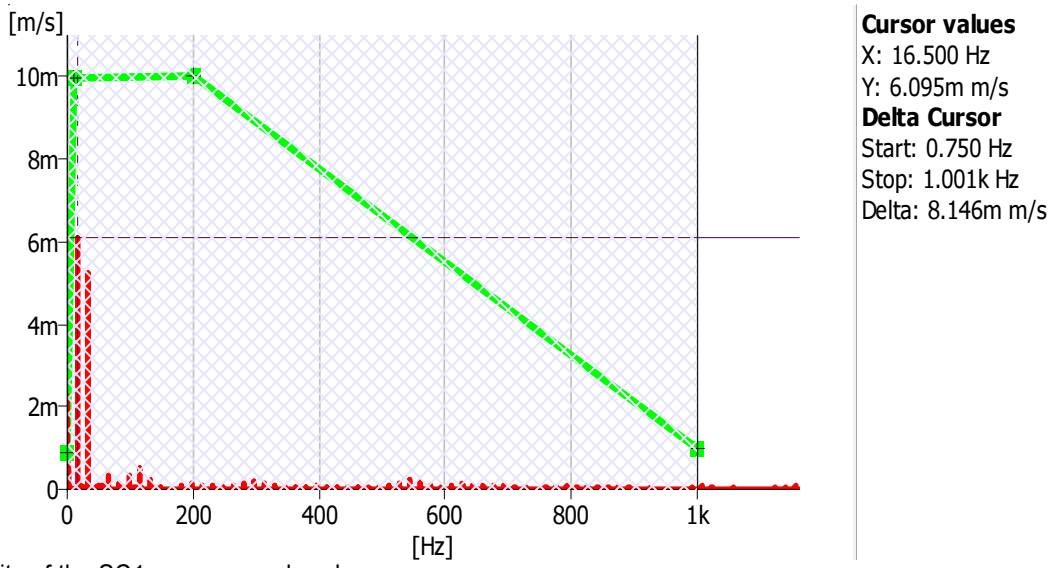

Fig. 7. Spectrum of vibration velocity of the SC1 compressor head

The spectrum of vibration velocity was highlighted in red in figure 7 . One can note some distinct lines of the $1^{\text {st }}$ and $2^{\text {nd }}$ harmonic vibration velocity typical for this type of equipmentwhich results from the work of the crank and piston system - $1^{\text {st }}$ harmonic, and the application of the two-stage and two-sided differential piston $-2^{\text {nd }}$ harmonic.

The tolerance curve for the vibration velocities recorded on the compressor heads, which follows from the EFRC guidelines (figure 2), has been marked in green. The hatched field represents a frequency range of $10 \mathrm{~Hz}-$ $1 \mathrm{kHz}$ from which a mean effective value of vibration velocity is calculated $v_{r m s}=8,146 \mathrm{~mm} / \mathrm{s}$. The $v_{r m s}$ was referenced with the value in the ISO 10816-6 standard table 1. 


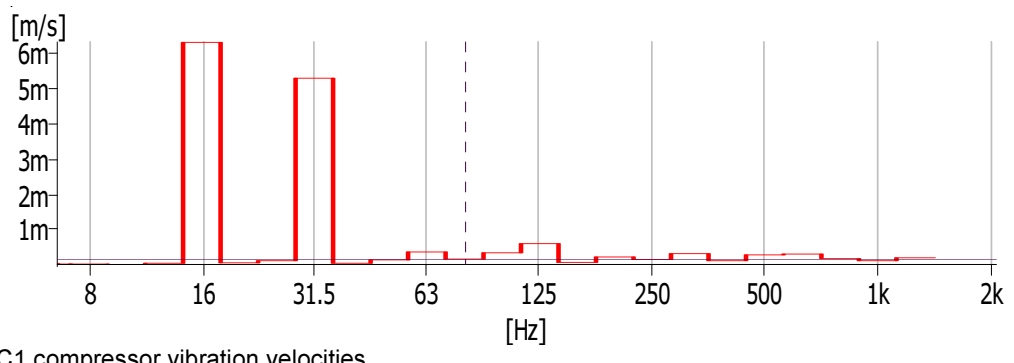

Fig. 8. 1/3 octave spectra of the SC 1 compressor vibration velocities

The last stage of vibration signal analyses was the application of the CPB method (Constant Percentage Bandwidth) to an amplitude-frequency vibration velocity, i.e. a method which consists of dividing the spectrum into intervals with constant bandwidth. $1 / 3$ octave spectra were selected where the bandwidth in relation to its frequency for all intervals was 0.232 . The values obtained in such a manner refer to the values given for $1 / 3$ octave bands in the NO-20-A500-3 standard.

The values of vibration parameters thus obtained in the course of the analyses meet the criteria for new machines and machines after repairs with an ample reserve, in relation to all normative acts referred to in the present paper. However, this is only valid for the SC-1 compressor. This follows from the fact that both compressors have a different construction and a different mounting. The waveform of absolute values of the $\mathrm{MCH}$ compressor vibration accelerations has been presented in figure 9.

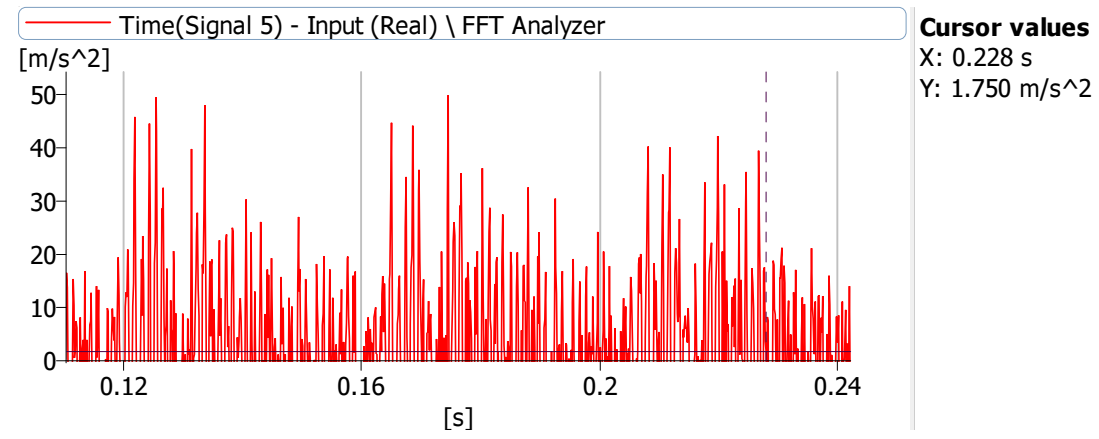

Fig. 9. Waveform of the $\mathrm{MCH}$ compressor vibration accelerations recorded on the head of the $3^{\text {rd }}$ stage compression.

A clearly noticeable interference of the vibration signal from the MCH compressor results not only from a larger complexity of the compressor, but also the application of belt transmission for the drive. However, the factor that contributes to such a waveform of vibrations in the highest degree is the mounting of the machine on a welded sheet steel foundation. The SC1 compressor is much heavier and sits on a rigid foundation.

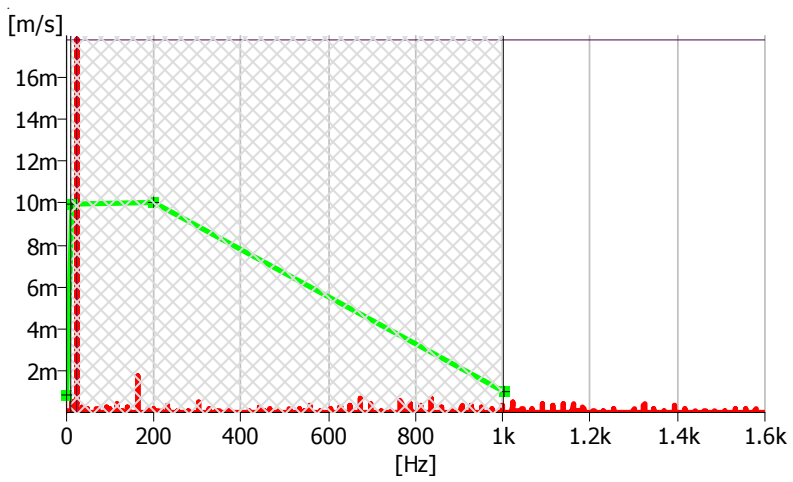

Fig. 10. Spectrum of vibration velocity of the $3^{\text {rd }}$ stage head in the SC1 compressor.
It is impossible to indicate the characteristic points of operation of the compressor on the waveform in fig 9 without prior filtration of the signal and introducing a synchronising signal that comes from e.g. the recording of the rotational speed of the crankshaft. The unfiltered waveform (fig 9) was analysed in terms of frequency according to the same principles as with the SC1 compressor. The result was presented in figure 10 .
Cursor values

$\mathrm{X}: 23.000 \mathrm{~Hz}$

Y: $17.800 \mathrm{~m} \mathrm{~m} / \mathrm{s}$

Delta cursor values

Delta: $20.337 \mathrm{~m} \mathrm{~m} / \mathrm{s}$

Delta Start: $9.750 \mathrm{~Hz}$

Delta Stop: $1.000 \mathrm{k} \mathrm{Hz}$ 
In the case of the $\mathrm{MCH}$ compressor, with regard to the EFRC guidelines (the green curve) the amplitude value equivalent to the first harmonic rotational speed of the crankshaft is clearly exceeded, which is a result of its sitting on the foundation mentioned previously.

Also the mean effective value of vibration velocity between $10 \mathrm{~Hz}$ and $1 \mathrm{kHz} \mathrm{v}_{\mathrm{rms}}=20.337 \mathrm{~mm} / \mathrm{s}$ is over twice as high as is the case of the same value recorded on the head of the SC1 compressor. Considerably higher values of vibration parameters in the case of the MCH compressor are also caused by its higher operating pressure. The impact of the pressure in the cylinder on the value of vibration velocity recorded on the head is shown in fig 11.

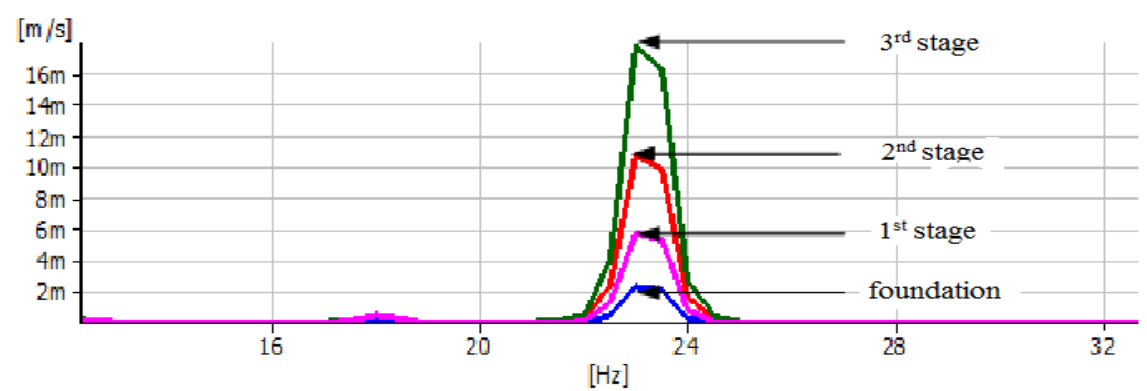

Fig. 11. Amplitude values of the first harmonic rotational speed recorded on consecutive degrees of compression, as well as on the foundation of the $\mathrm{MCH}$ compressor

\section{Conclusions}

Lack of clearly defined levels of allowable vibration parametersconsiderably affects a quick determination of the technical condition by the diagnostician on the basis of a single round of measurements. This applies only to compressors of less than $100 \mathrm{~kW}$.

In the course of the preparation of the present paper, a number of measurements were performed on two types of compressors of $10 \mathrm{~kW}$ and $4 \mathrm{~kW}$. They are different from each other in terms of construction, efficiency, maximum operating pressure and the manner in which they are mounted on their foundation.

A division into devices that are rigidly laid on foundations and with maximum operating pressures up to $5 \mathrm{MPa}$, and those which are flexibly placed with maximum pressures higher than $5 \mathrm{MPa}$ is suggested as reasonable. The provision of specific values for respective sampling points requires a number of further tests on a higher number of devices in varying technical conditions.

At this point, the observance of the EFRC guidelines is recommended, yet caution is suggested when evaluating the spectrum with special reference to high-frequency components (over $200 \mathrm{~Hz}$ ). Such components in an efficient compressor should have minimal values. The dominant components of the amplitude-frequency spectrum in an efficient compressing unit driven by an electric motor should be the first harmonic and its multiples. The number of the multiples will correspond to the degree of compressing.

It should be underlined that referring only to the values defined in the standards while making analyses of vibration parameters is inappropriate. This is not diagnostics but monitoring the technical condition of the equipment. A diagnostician must be able to identify the difference between vibrations that indicate a problem with the compressor, and those which are related to its construction and principles of operation.

There have been instances of machines being damaged although vibration parameters defined in the standards were not exceeded. On the other hand, it has been recorded on multiple occasions that the device was fully operational in technical terms in spite of exceeding the parameters set out in the standards (e.g. figure $10-$ the $\mathrm{MCH}$ compressor).

THE AUTHOR IS THE LAUREATE OF THE IV ANTONI DĘBSKI SCHOLARSHIP COMPETITION.

\section{BIBLIOGRAPHY}

Białek P., Bielawski P., Vibration signals of reciprocating compressor valves, Journal of Polish CIMAC, vol. 8, no. 1, 2013, ISSN 1231-3998;

European Forum Reciprocating Compressors (EFRC), Guidelines for Vibrations in Reciprocating Compressor Systems, Third Edition May 2012;

ISO 10816-6: Mechanical vibration-Evaluation of machine vibration by measurements on non-rotating parts- Part 6: Reciprocating machines with power

ratings above $100 \mathrm{~kW}$. First edition 1995-12-15;

4. Górski, Z., Perepeczko, A., Okrętowe maszyny i urządzenia pomocnicze, tom I [Ship machines and ancillary devices], Trademar, Gdynia 1997;

5. Listewnik K., Polanowski S., Dereszewski M., Zukowski J., Preliminary evaluation of effective vibration analysis for the fault diagnosis of natural gas engine-driven compressor, Journal of KONES Powertrain and Transport, Vol. 18, No. 4 2011;

6. M Ahmed, F Gu and A D Ball, Fault Detection of Reciprocating Compressors using a Model from Principles Component Analysis of Vibrations, Journal of Physics: Conference Series 364 (2012) 012133;

7. Defence Standard NO-20-A500-3, Technical requirements and the inspection of ship's devices and machinery Vibrations Measurements and criteria for evaluation;

8. Shelley D. Greenfield, Luis de la Roche, Introduction to Vibration \& Pulsation in Reciprocating Compressors, Beta Machinery Analysis Ltd., Calgary, AB, Canada, T3C 0J7:

9. www.emerson.com;

10. www.bentlynevada.com;

11. www.coltrisub.it;

12. Yih-Hwang Lin a, Wen-Sheng Lee, Chung-Yung Wu, Automated Fault Classification of Reciprocating Compressors from Vibration Data: A Case Study on Optimization using Genetic Algorithm, Procedia Engineering 79 ( 2014 ) 355 - 361, 1877-7058. 
mgr inż. Marcin Kluczyk

Instytut Budowy i Eksploatacji Okrętów, Akademia Marynarki Wojennej

ul. Śmidowicza 69, Gdynia

tel: 261262654

e-mail: m.kluczyk@amw.gdynia.pl 